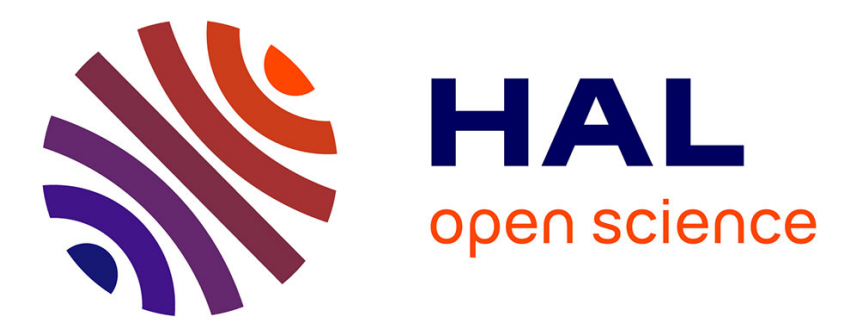

\title{
Preservative Approach to Study Encased Archaeological Artefacts
}

Théophane Nicolas, Ronan Gaugne, Cédric Tavernier, Valérie Gouranton, Bruno Arnaldi

\section{- To cite this version:}

Théophane Nicolas, Ronan Gaugne, Cédric Tavernier, Valérie Gouranton, Bruno Arnaldi. Preservative Approach to Study Encased Archaeological Artefacts. International Conference on Culturage Heritage, EuroMed, 2014, Nov 2014, Lemessos, Cyprus. pp.332 - 341, 10.1007/978-3-319-13695-0_32 . hal01090157

\section{HAL Id: hal-01090157 \\ https://hal.science/hal-01090157}

Submitted on 4 Dec 2014

HAL is a multi-disciplinary open access archive for the deposit and dissemination of scientific research documents, whether they are published or not. The documents may come from teaching and research institutions in France or abroad, or from public or private research centers.
L'archive ouverte pluridisciplinaire HAL, est destinée au dépôt et à la diffusion de documents scientifiques de niveau recherche, publiés ou non, émanant des établissements d'enseignement et de recherche français ou étrangers, des laboratoires publics ou privés.

\section{(ㄷ)(1)}

Distributed under a Creative Commons Attribution| 4.0 International License 


\title{
Preservative Approach to Study Encased Archaeological Artefacts
}

\author{
Théophane Nicolas' ${ }^{1}$, Ronan Gaugne ${ }^{2}$, Cédric Tavernier ${ }^{3}$, Valérie Gouranton ${ }^{4}$, \\ Bruno Arnaldi ${ }^{4}$ \\ ${ }^{1}$ Inrap, France \\ ${ }^{2}$ Université de Rennes 1/IRISA, France \\ ${ }^{3}$ Image ET, France \\ ${ }^{4}$ Insa de Rennes/IRISA, France
}

\begin{abstract}
We propose a workflow based on a combination of computed tomography, 3D images and 3D printing to analyse different archaeological material dating from the Iron Age, a weight axis, a helical piece, and a fibula. This workflow enables a preservative analysis of the artefacts that are unreachable because encased either in stone, corrosion or ashes. Computed tomography images together with $3 \mathrm{D}$ printing provide a rich toolbox for archaeologist work allowing to access a tangible representation of hidden artefacts. These technologies are combined in an efficient, affordable and accurate workflow compatible with Preventive archaeology constraints.
\end{abstract}

Keywords: Tomography, 3D modelling, 3D printing, Digital heritage,

\section{Introduction}

Preserving archaeological material while analysing it, is a major concern for archaeologists. This problematic is often difficult to address because studied artefacts may be encased in corroded materials or a block of block of cremated bones, or integrated with, and inseparable from, larger assemblies, such as manufactured objects composed of several pieces. Once a material is destroyed, hypotheses on the original structure become unverifiable.

In this paper, we aim to propose a workflow for analysing archaeological artefacts by combining computed tomography with $3 \mathrm{D}$ printing, which is non-destructive, and accurate enough to perform further analysis. We can apply this methodology on three different contexts:

- Analysis of the internal iron-made axis of an Iron Age weight;

- Evaluation of the interest to restore a completely corroded piece;

- Study of objects sealed in a block of block of cremated bones.

Computed tomography (CT) [2] is an imaging technology widely used in medicine, CT scanners use computer-processed $\mathrm{x}$-rays to produce tomographic images (virtual «slices») of specific areas of the scanned object.

The use of CT technologies for the analysis of historical artefacts is not new but remains limited, due to the difficulties of carrying this type of analysis on a large scale with appropriate access to equipment and trained personnel, and for exploiting the obtained digital data. Furthermore, the existing examples of such images for cultural heritage are mostly related to analysis of human or animal remains (e.g. 
mummified materials) but there are few cases of other materials being examined, such as non-organic archaeological material [3], [4]. All of previous projects exploit the acquired images in their usual format, and do not combine them with other 3D technologies. The work presented in [5] proposes to use of 3D printers to reproduce a chess piece for study purposes. This work illustrates one possible bridge between medical images and 3D technologies.

3D technologies are widely used in archaeology and cultural heritage domains [6], [7], but mainly associated to 3D modelling, photogrammetry or lasergrammetry.

Our paper proposes to combine these two approaches to provide new tools for the preservation and analysis of archaeological artefacts.

\subsection{Archaeological Context of the Work}

The excavation of the site la Claraiserie, in Ossé (Brittany, France), revealed part of an Iron Age farm and field systems (Excavation J. Gall, Inrap). The site was occupied from the second century BCE. The remains of several earth and timber buildings were uncovered, together with a large number of iron objects contained within a pit. These were identified as agricultural tools, hunting weapons, horsebits as well as elements from a set of scales, probably used for weighing the farm produce. These included several spherical weights made out of granite. The weight studied here has a diameter of $8 \mathrm{~cm}$ for a weight of 620 grams. It is perforated axially, with an iron made axis attached to a ring inserted in the perforation, in order to allow the suspension of the weight (Fig.1a).
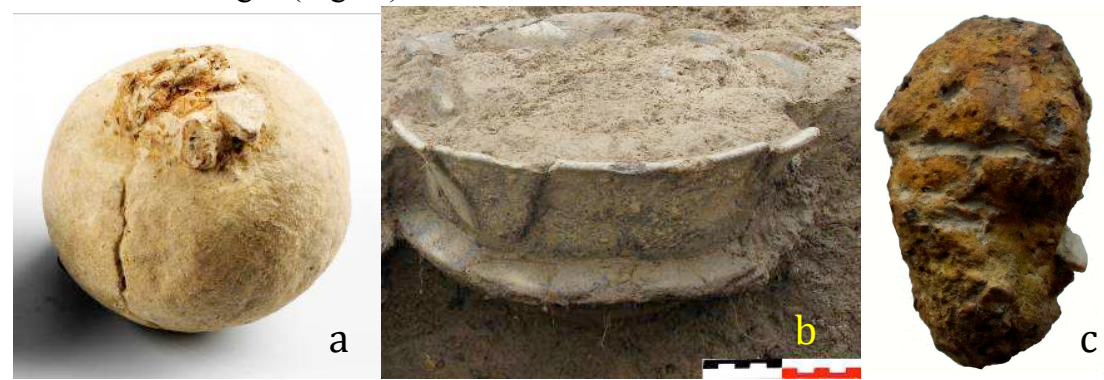

Fig. 1- a: granite weight, b: F42A cremation from Guipry, in situ, c: External view of the helical piece

The excavation of the site of Domaine de la Bizaie in Guipry (Brittany, France) uncovered a trapezoidal shaped funerary enclosure the central area housing ten cremation burials containing pottery vessels dating to the Iron Age (Excavation L. Aubry, Inrap). The exceptional state of preservation of some of these cremations prompted us to use tomography to analyse their contents. In some case, a number of metal objects were highlighted as in the F42A cremation (Fig. 1b) containing a fibula and a knife blade.

The excavation of the site la Salmondière in Cesson-Sévigné (Brittany, France) revealed a long occupation dating from the Bronze Age to medieval times (Excavation J.-C. Durand, Inrap). From about $250 \mathrm{BC}$ to the end of the Iron Age (80 $\mathrm{BCE})$, the occupation of the site is characterized by the establishment of a large 
agricultural area. Many finds, in particular metallic objects, have been recovered from the site. A complete radiographic survey for iron objects was performed, combined with tomography for the more complex objects. This survey allowed us to identify corroded objects that would not otherwise have been possible. This is the case of the helical small piece, $4.5 \mathrm{~cm}$ long and $1.3 \mathrm{~cm}$ in diameter with 7 turns, studied in this work. This piece was completely covered by a thick layer of rust (Fig. 1c).

\subsection{Presentation of the Approach}

While the contexts of the three use cases studied in this paper are completely different, there exists a common characteristic: the parts of the artefacts we wanted to study were unreachable. In the case of the Iron Age weight, the metal axis was encased in the stone part, and covered by rust. Concerning the cremation, the different objects were sealed in the block of cremated bones. In the case of the helical piece, the archaeologists wanted to identify and evaluate the interest the piece completely covered by a corrosion layer before launching a long and costly conservation and restoration process.

Before any destructive analysis, all the archaeological material was digitized with computed tomography. The aim of the work was to provide $3 \mathrm{D}$ views and tangible material to archaeologists in order to ease the study of unreachable parts of the original material. In order to fulfil this goal, we combined 3D images technologies and $3 \mathrm{D}$ printing.

The same approach was applied to the three object we wanted to study:

1. A computed tomography of the archaeological material was performed generating a database of X-Ray images.

2. Volume 3D views are generated for interesting parts of the material

3. Surface 3D models are generated, processed and printed

The volume $3 \mathrm{D}$ views and $3 \mathrm{D}$ printed objects are specifically dedicated to the archaeologist work for study purposes. Their generation required engineers with specific skills, with the participation of an archaeologist to validate the interest of the resulting data.

\section{Work Description}

We will now present the technical workflow applied to the different artefacts studied in this work.

\subsection{Technical Environment}

The technical environment is composed of three parts, tomography scanner, 3D images processing, and $3 \mathrm{D}$ printing. 
Tomography. The CT scanner used in this study is a Siemens SOMATOM sensation 16 (Fig. 2). It is owned by the French company Image ET1 who delivers services and expertise on X-Ray images and associated tools.
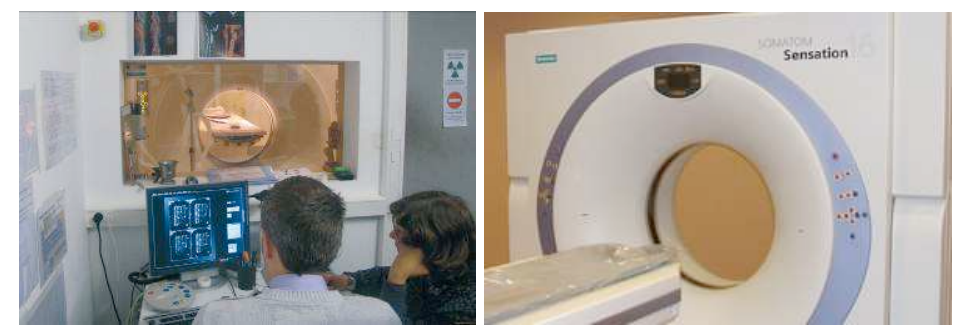

Fig. 2: The CT scanner in Image ET

The three-dimensional explorations were performed through two passes (acquisition) and $2 \mathrm{D} / 3 \mathrm{D}$ images post-processing. The two acquisitions were a topogram (or radio mode) for positioning the slices to be realized and a helix scan.

The global methodology is similar for all the scans processed in this work. The only differences are in $\mathrm{kV}$ and $\mathrm{mAs}$ values, and in the resolution of the cutting map (XY) which depends of the field of view, the matrix of the $2 \mathrm{D}$ slice images being constant (512x512 pixels) on the scanner.

The scan generates a dataset under DICOM format [8].

Image processing. The data generated during the CT scan was processed with the software Osirix2, an image processing application for Mac dedicated to DICOM images, under free software license. Two post-processing functionalities of Osirix were used in the current work, the 3D volume rendering and the 3D surface rendering. The $3 \mathrm{D}$ surface rendering generates $3 \mathrm{D}$ meshes that were processed with the $3 \mathrm{D}$ modelling tools Blender3, and Meshlab4 to be ready-to-print.

3D printing We used two different 3D printers (Fig. 3) for the production of the copies. For the weight, we used a MarkerBot Replicator 2x. For the fibula and the helical piece, we used a Stratasys MOJO. The MakerBot Replicator 2X 3D Printer uses Fused Filament Fabrication to print objects from ABS. Using 2 extruder head(s), it prints objects in layers as thin as 100 Microns, with a maximum dimension of $15.2 \mathrm{~cm}$ wide, $15.5 \mathrm{~cm}$ high and $24.6 \mathrm{~cm}$ long. The Stratasys Mojo 3D Printer uses Plastic Jet Printing to print objects from ABS. Using 2 extruder head(s), it prints objects in layers as thin as 178 Microns, with a maximum dimension of $12.7 \mathrm{~cm}$ wide, $12.7 \mathrm{~cm}$ high and $12.7 \mathrm{~cm}$ long.

\footnotetext{
${ }^{1} \mathrm{http}: / / \mathrm{www}$.image-et.fr/

${ }^{2} \mathrm{http}: / /$ www.osirix-viewer.com/

${ }^{3} \mathrm{http}: / /$ www.blender.org/

${ }^{4} \mathrm{http}: / /$ meshlab.sourceforge.net/
} 
We chose to use the Mojo printer for smaller pieces because the resulting pieces were more accurate. The Replicator printer was used for larger pieces and better coloured rendering.
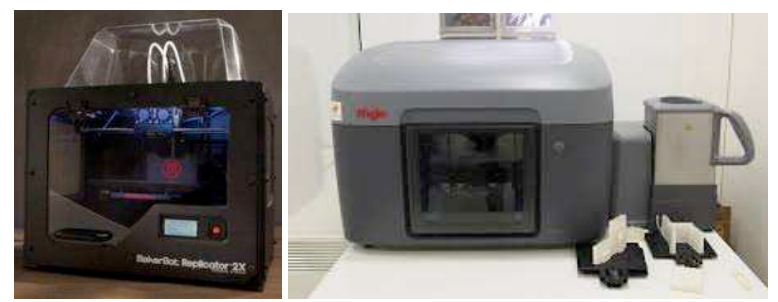

Fig. 3: Left : MakerBot Replicator 2X Right : Stratasys Mojo

\subsection{The Iron Age Weight}

The technical data for the scan of the weight is the following:

\begin{tabular}{|c|c|c|c|}
\hline $\mathbf{k V}$ & mAs & FoV & Resolution \\
\hline $140 \mathrm{kV}$ & $500 \mathrm{mAs}$ & $112 \mathrm{~mm} \times 112 \mathrm{~mm}$ & $218 \mu$ \\
\hline
\end{tabular}

The $\mathrm{kV}$ and $\mathrm{mAs}$ values represent the parameters of the $\mathrm{X}$ rays intensity, influencing the penetration of the $\mathrm{X}$ rays $(\mathrm{kV})$ and the clearness of the image $(m A s)$. The FoV, for Field of View, depends on the size of the zone we want to focus on. The resulting image is projected on an invariant $512 \times 512$ pixels matrix, inducing the resolution.

The scan of the weight allowed us to focus on the iron axis inserted in granite and covered by rust. The highlight of the different components of the material is based on density information calculated during the CT scan, called the radiodensity, and expressed relatively to the Hounsfield scale [9]. The 3D volume reference image presented in the left of Fig. 4 was generated with four colours, modifying the opacity of each colour with respect to the level of radiodensity. The display rules are presented in Fig. 5, the cyan layer around the weight generated by the beam hardening artifacts (corresponding to the air / material interface) is used to strengthen the visualisation. The image on the right of Fig. 4 was generated with only two colours, with different parameters in order to focus on the iron axis. 


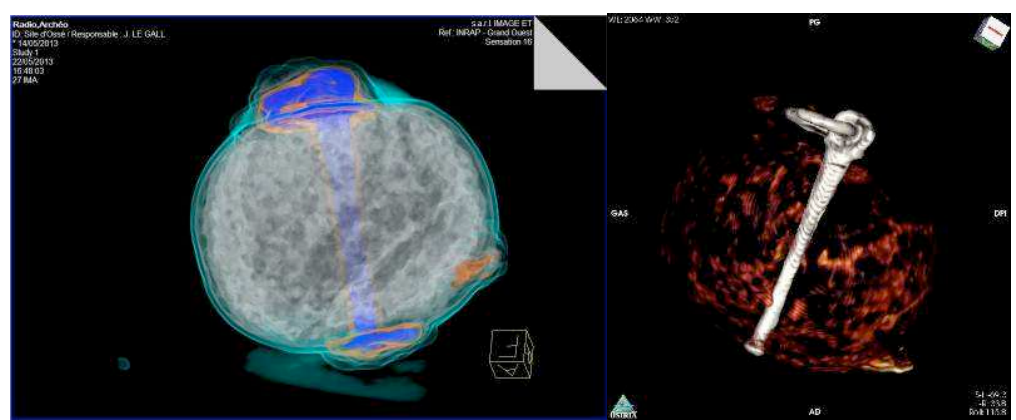

Fig. 4: 3D views of the weight

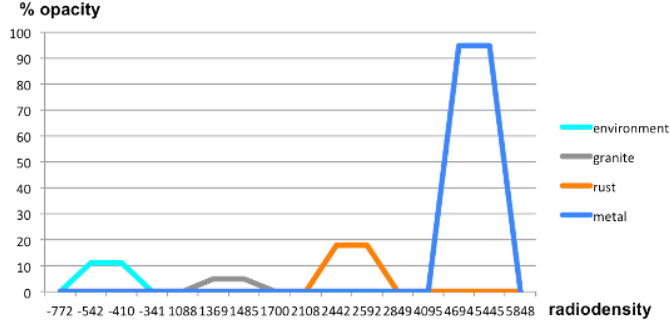

Fig. 5: 3D volume rendering values for the weight

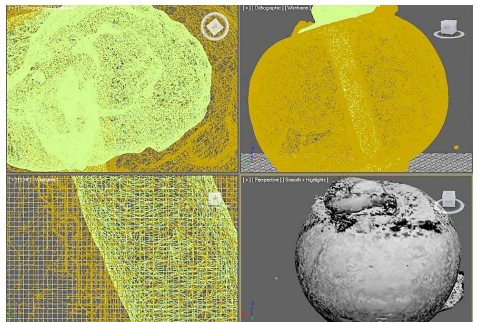

Fig 6 : resulting mesh

The 3D surface renderer of Osirix is used to produce the mesh destinated to the 3D printer. The mesh is constructed as the surface of the point cloud correspondig to an interval of radiodensity values. For the granite part, the values considered are in the interval [300;2000]. For the metal part, the interval considered is greater than 3000 .

The mesh obtained with Osirix was exported in obj format and processed with Blender and Meshlab to clean the generated mesh in order to obtain a ready-to-print 3D model. The mesh for the granite part was cut in two parts along the axis hole in order to access to the iron axis and study the positioning of the axis inside the granite sphere. The 3D models were printed with the Replicator printer, in two colours to have a clear distinction between the different parts of the weight (Fig. 7)
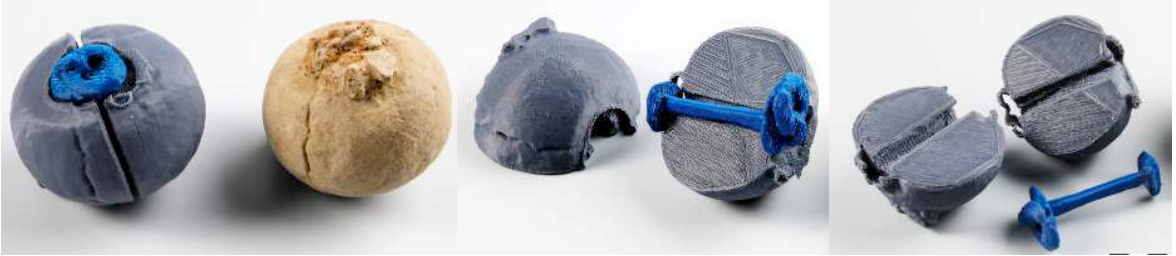

Fig. 7: 3D printed copy of the weight

\subsection{Helical Piece Study}

The technical data for the scan of the weight is the following:

\begin{tabular}{|c|c|c|c|}
\hline $\mathbf{k V}$ & mAs & FoV & Resolution \\
\hline $140 \mathrm{kV}$ & $350 \mathrm{mAs}$ & $50 \mathrm{~mm} \times 50 \mathrm{~mm}$ & $97 \mu$ \\
\hline
\end{tabular}


In order to highlight the helical piece, the $3 \mathrm{D}$ volume rendering was generated with two colours according to the values of Fig. 8. The resulting rendering is presented in Fig. 9. These images provide a very good quality view of the helical piece inside rust. The $3 \mathrm{D}$ surface rendering was generated for radiodensity values greater the 6500 (Fig10).
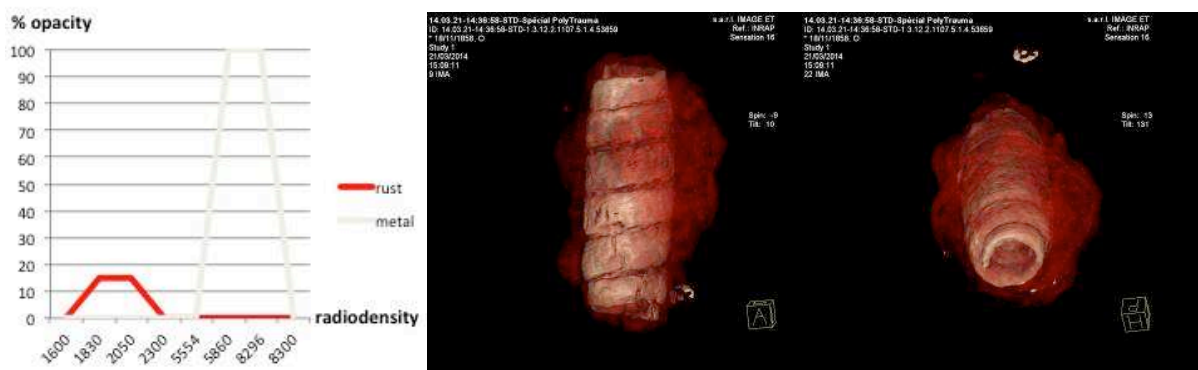

Fig. 8: 3D volume rendering values

Fig. 9: 3D views of the helical piece
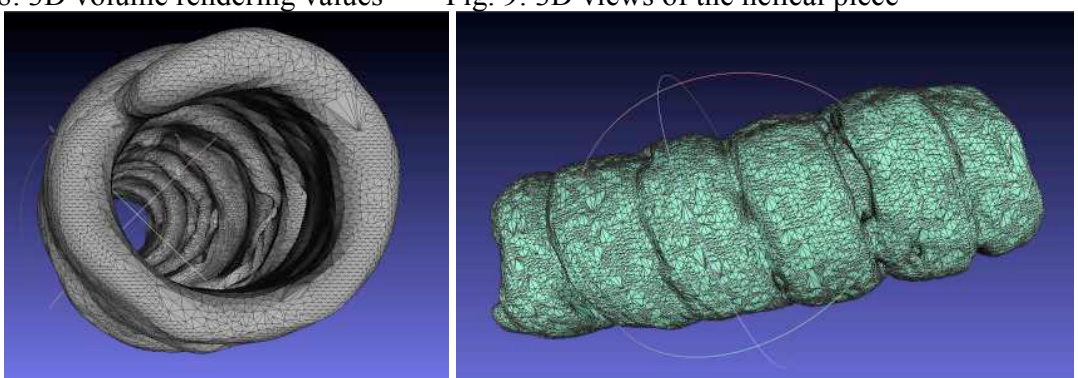

Fig. 10: 3D views of the helical piece
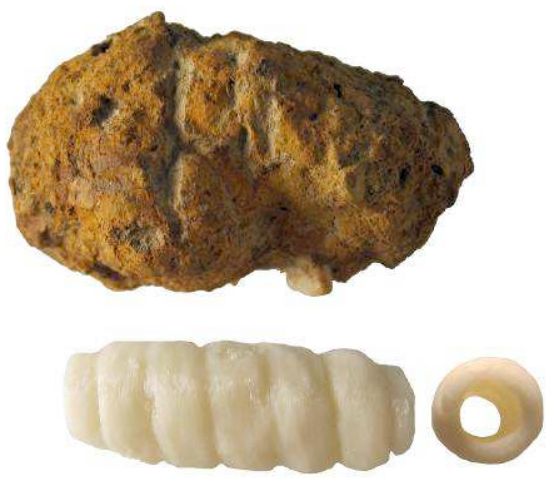

Fig. 11: 3D printed copy of the helical piece

The mesh was exported in obj format and processed with Meshlab to be cleaned and exported in stl format which is the fomat acceptable for the Mojo printer. The lateral and front views of the resulting 3D printing, compared to the real object are presented in Fig. 11. 


\subsection{Fibula Study}

The technical data for the scan of the weight is the following:

\begin{tabular}{|c|c|c|c|}
\hline $\mathbf{k V}$ & mAs & FoV & resolution \\
\hline $120 \mathrm{kV}$ & $350 \mathrm{mAs}$ & $320 \mathrm{~mm} \times 320 \mathrm{~mm}$ & $625 \mu$ \\
\hline
\end{tabular}

The aim of the volume rendering was to highlight objects with different density than ashes. We worked in an extended Hounsfield scale (from -10.000 to +40.000 ), to get a finer view of the metallic objects and focused on two density intervals, one between 1600 and 2300 corresponding to bones represented in red, and one between 4500 and 10950 corresponding to metallic objects, represented in blue. In order to keep a view of the ash block, which has a heterogeneous density, we took a large interval with a variation of the opacity to get a uniform representation, in grey, of the urn shape. The association of the radiodensity values is presented in Fig 12, and the volume 3D rendering, in Fig. 13. The resulting 3D mesh is presented in Fig. 14.

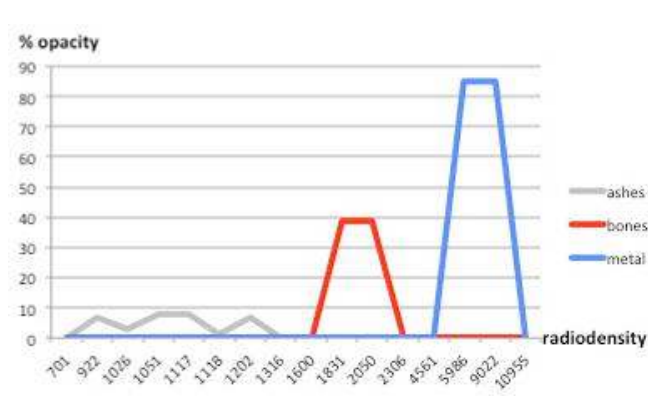

Fig. 12: rendering values
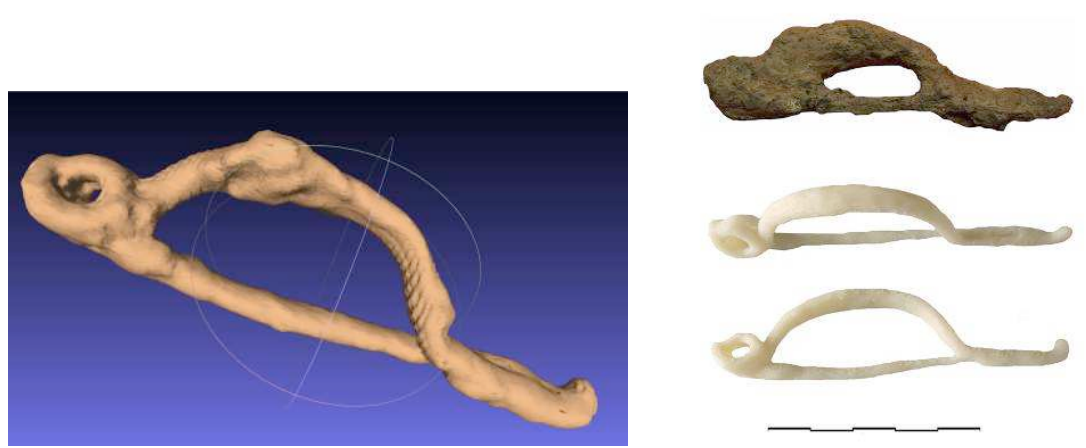

Fig. 14: 3D mesh of the fibula Fig. 15: 3D printed fibula

\section{Discussion}

New technology in imaging, that has until now been exclusively used by museums and applied to the study of remarkable objects, has opened up new perspectives in Preventive Archaeology. This hitherto unused method has revealed to be an amazing tool for the scientific study of archaeological artefacts providing precious information 
as to the preservation and the protection of the most fragile of objects. It has many advantages. It is a non destructive method that can be used for the examination and study of fragile or non-visible objects in need of immediate consolidation (conglomerate of objects, oxidized object) or for a preliminary examination of objects that will undergo laboratory excavation (for example a cremation burial in an urn), as it provides a $3 \mathrm{D}$ visualisation or can be used to create a facsimile using 3D printing. This considerably reduces the manipulation of the object itself. Also, as excavation and the cleaning of artefacts are non-reversible, the imagery and 3D printing become a permanent virtual record of the object's original state thus allowing ulterior observations and study. This process saves time as it facilitates the identification and analysis and so is perfectly adapted to preventive archaeology. It is also possible to determine material density providing valuable information as to the preservation of the object and its fragility, helping to make the right choice concerning the methods required for cleaning and conservation.

Analysis of the weight with tomography highlights elements that are invisible to the eye such as the ring which is encased in the gangue corrosion. It also allows to access some parts without having to break the object such as the iron axis inserted in the granite sphere. The 3D printing of the sphere and axis allows the manipulation of these elements, and identifying and/or discussing technical choices of the implementation (insertion of the metal stem in the sphere, drawing of two perforated plates placed on either side of the latter), but also clues to the manufacture of the axis (facets hammering...) hardly noticeable with tomography.

If in the case of the balance weight, the object is identifiable, this is not the case with the helical piece. First, tomography characterized an object that cannot be identified by the naked eye and hardly recognizable with simple radiography. The acquisition of a 3D model of this item helped with identification and description; associated to a $3 \mathrm{D}$ printing, that process appears to be a quick and inexpensive alternative to study this kind of object. It also gives clear indications to the archaeologists as to later restorations (object category and preservation state) and to the restorer (location of the object in the matrix, differential density of materials, composite assemblies identification).

In the case of the cremations, tomography allows spatial localisation of all artifacts and their identification. If modelling indicates how the objects were organized in the burial (in particular the cremated bone), it mainly serves to rapidly determine if the deposits contain sensitive objects such as metal. This information allows us to anticipate optimally fine analysis of clusters and to implement protective measures for artefacts. 3D acquisition associated to 3D printing offers the possibility to duplicate an artefact amongst others, leading to an immediate typological identification of the artefact, as well as morphological, typo-metric or technological observations, regardless of contingencies relative to conservation and restoration operations often required by such objects.

Nevertheless, there are still some efforts to do in order to adapt these technologies for the specificities of archaeological and cultural heritage. In particular, the software related to DICOM image processing is very well suited for medical applications but would require some adaptations for archaeological objects (focus on the volume and surface 3D rendering, better handling of extended Hounsfield scale more adapted to dense material such as metal). 


\section{Conclusion and Future Works}

Associating tomography and 3D printing offers many opportunities for the study of archaeological objects especially composite or oxidized metal; if this process is a precious tool in the identification of corroded objects, it also helps to identify and characterize complex objects, or technical characteristics. It also contributes to the development of specific protective measures for artifacts, as well as operational support during the restoration phase

The copies made of objects can be used for exhibition in particular when the state of preservation does not allow restoration. It is also a great educational tool highlighting the hidden side of some composite objects or even the functionality of certain mechanisms.

It appears that if, today, these tools are mainly used in the cases of exceptional discoveries, it is clear that their fields and conditions of application are fully in tune with those of preventive archaeology.

Acknowledgments. The authors wish to thank Guillermo Andrade (Inria) and Yann Macé (ENS de Rennes) for their work on 3D printing, and Rebecca Peake (Inrap) for her kind support.

\section{References}

1. Lai, C.M., House, W.V., Lauterbur, P.C.: Nuclear magnetic resonance for medical imaging. In Proc. of IEEE/ERA Technology for non-invasive monitoring of physiological phenomena. Electro/78. pp1-15, (1978).

2. Herman, G. T.: Fundamentals of computerized tomography: Image reconstruction from projection, 2nd edition, Springer, (2009)

3. X-rays for Archaeology, Edited by M. Uda, G. Demortier and I. Nakai, Springer, (2005)

4. Hughes, S.: CT Scanning in Archaeology, in Computed Tomography - Special Applications, L. Saba Ed., InTech, (2011)

5. Laycock, S., Bell, G., Mortimore, D., Greco, M., Corps, N., Finkle, I.: Combining X-Ray Micro-CT Technology and 3D Printing for the Digital Preservation and Study of a 19th Century Cantonese Chess Piece with Intricate Internal Structure, in ACM Journal on Computing and Cultural Heritage, Vol. 5, No. 4, (2012)

6. Arnold, D., 3D-COFORM: Tools and Expertise for 3D Collection Formation, in Proceedings of EVA 2009 Florence Eds. V. Cappellini and J. Hemsley, (2009)

7. Havemann, S., Settgast, V., Fellner, D., Willems, G., Van Gool, L., Muller, G., Schneider, M., Klein, R.: The Presentation of Cultural Heritage Models in Epoch, Open Digital Cultural Heritage Systems, EPOCH Final Event Rome, (2008)

8. Mustra, M., Delac, K., Grgic, M.: Overview of the DICOM Standard. ELMAR. 50th International Symposium. pp. 39-44, (2008)

9. Molteni, R. From CT numbers to Hounsfield Units in cone beam volumetric Imaging: the effect off artifacts. AAOMR, Chicago (2011) 